\title{
Los derechos humanos como precondiciones de la democracia: evidencia desde México*
}

\section{Rocío Flores Calderón** Orlando Espinosa Santiago***}

\section{RESUMEN}

En la literatura se acepta que la democracia minima fortalece la protección de los derechos humanos. Sin embargo, poco se sabe de cómo se comporta esta relación en paises de reciente democratización, como México. De acuerdo con los estudios previos, a la par de la consolidación democrática, se debería observar una disminución de violaciones a los derechos humanos. Mientras que en paises de reciente democracia, se debería observar un incremento de las violaciones. La evidencia empírica recopilada del caso mexicano no se ajusta a las dos hipótesis predominantes de la literatura. Podría tratarse de un caso anómalo. Ouizá la política del combate al crimen organizado sea la causa principal de dicha anomalía, con un impacto negativo en la solidez de las precondiciones indispensables para que funcionen las reglas de la democracia.

PALABRAS CLAVE: Democracia, precondiciones, derechos humanos.

\section{ABSTRACT}

In the literature, it is accepted that minimal democracy strengthens the protection of human rights. Nevertheless, little is known about how in countries of recent democratization, as Mexico, this relation behaves. In accordance with the previous studies, in line with democratic consolidation, it should be noted a decrease of human rights violations. Whereas in countries of recent democracy, it should be noted an increase of the violations. The empirical evidence on the Mexican case does not correspond to the predominant hypotheses of the literature. It might be an anomalous case. Perhaps the politics of the combat to organized crime is the main cause of this anomaly, with a negative impact on the strength of the essential preconditions so that the rules of democracy work.

KEY WORD: Democracy, preconditions, human rights

* Artículo recibido el 13 de diciembre de 2016 y aceptado el 2 de marzo de 2017.

** Candidata a Doctora en Ciencias de Gobierno y Política, y profesor-investigador en el Instituto de Ciencias de Gobierno y Desarrollo Estratégico de la Benemérita Universidad Autónoma de Puebla. (rocio.flores@correo.buap.mx)

*** Profesor-investigador en el Instituto de Ciencias de Gobierno y Desarrollo Estratégico de la Benemérita Universidad Autónoma de Puebla. (orlando.espinosa@correo.buap.mx) 


\section{SUMARIO}

1. Introducción

2. Teorías procedimentales de la democracia y precondiciones de la democracia

3. Fortalecimiento de la democracia competitiva

4. Evidencia empírica

5. Conclusiones

\section{Introducción}

Tanto para los estudiosos de la política como para los estudiosos del derecho, el régimen político que ofrece mejores condiciones para la protección de los derechos humanos es el democrático. ${ }^{1}$ Sin embargo, dentro de la teoría política suelen distinguirse varios modelos de democracia que implican una cierta postura sobre los derechos humanos. Algunos, más de carácter sustantivo, buscan la resolución de condiciones sociales y económicas (democracia sustantiva); otros, más civiles y políticos, posibilitan la participación en una comunidad política (democracia procedimental).

Consideramos que la democracia procedimental explica mejor el fortalecimiento de los derechos humanos en el caso mexicano, en tanto la presencia de ciertas precondiciones derivó en una transición a la democracia mediante reformas electorales. Para evidenciar el vínculo negativo entre democracia y derechos humanos se suele considerar países de democracias consolidadas; sin embargo, poco se sabe de esta relación en democracias provenientes de autoritarismos hegemónicos, como lo fue el mexicano.

Aunque a nivel global se reconoció la presencia de la tercera gran transformación de la democracia,${ }^{2}$ la misma no fue uniforme en todas las regiones. América Latina y Europa del Este fueron el escenario de la última oleada, y nuestro país en particular suele incluirse como ejemplo de democratización rezagada y reciente en términos históricos. Más allá de los distintos escenarios donde puede validarse la teoría, a partir de la literatura esperamos: 1) que en democracias consolidadas la violación de los derechos humanos disminuya, y 2) que en democracias no consolidadas la violación de los derechos humanos incremente.

\footnotetext{
'Christiano, Thomas, "An Instrumental Argument for a Human Right to Democracy", Philosophy \&t Public Affairs, 2011, vol. 39, núm. 2.

${ }^{2}$ Dahl, RoBert, La democracia y sus críticos, Barcelona, Paidós, 1992.
} 
Para analizar el comportamiento de la relación entre estas dos variables en el caso mexicano, este texto se compone de cinco partes. La primera es la presente introducción. En la segunda, se desarrolla sucintamente la teoría democrática procedimental y se muestra la conexión entre la teoría procedimental de Bobbio y la teoría de los derechos humanos en términos de las precondiciones. En la tercera, se aborda el fortalecimiento de la democracia competitiva. En la cuarta, se muestra la evidencia empírica a partir de fuentes oficiales disponibles comparables. En la quinta, se presentan conclusiones sobre los hallazgos y la agenda de investigación.

\section{Teorias procedimentales de la democracia y precondiciones de la democracia}

La teoría política identifica cuatro tipos de posturas respecto a la democracia, mismas que proponen definiciones del concepto: la constitucional, la sustantiva, la procedimental y la orientada al proceso. ${ }^{3}$ La definición constitucional hace referencia a las leyes emitidas por un régimen en relación con la actividad política. Por su parte, la definición sustantiva se concentra en las condiciones políticas y de vida que un régimen específico promueve. A diferencia de las dos anteriores, la definición procedimental identifica ciertas prácticas gubernamentales que constituyen el criterio para determinar si un régimen califica como democrático o no. Finalmente, la definición orientada al proceso identifica un conjunto mínimo de procesos que tienen que estar presentes y en continuo desenvolvimiento para que una situación califique como democrática. ${ }^{4}$

La postura procedimental afirma que ciertas reglas determinan qué corresponde a la voluntad colectiva. Éstas son las reglas constitutivas y permiten que la soberanía se traduzca en democracia, en la forma de leyes generales que serán aplicadas materialmente a individuos específicos. ${ }^{5}$ Dentro de la vertiente procedimental de la democracia, destaca la propuesta de Norberto Bobbio, quien define a la democracia mínima como "una forma de gobierno, caracterizada por un conjunto de reglas (primarias y secundarias) que establecen quién está autorizado para tomar las decisiones colectivas y bajo qué procedimientos". ${ }^{6}$ Esta definición mínima de la democracia se traduce usualmente en la legislación y

\footnotetext{
${ }^{3}$ Tilly, Charles, Democracy, Cambridge, Cambridge University Press, 2007, p. 7.

${ }^{4}$ Tilly, Charles, Democracy, Cambridge, Cambridge University Press, 2007, pp. 8-11.

${ }^{5}$ Greppl, Andrea, "Definiciones y reglas de la Democracia", en Lorenzo Cordova y Pedro Salazar (coords.), Política y derecho: (re) pensar a Bobbio, México, Siglo XXI, 2005, pp. 129-148.

${ }^{6}$ Bobbio, Norberto, El futuro de la democracia, México, FCE, 2001, p. 24. Las cursivas son nuestras.
} 
disposiciones que en su conjunto definen al sistema electoral, cuyo fin es traducir los votos ciudadanos en escaños parlamentarios o cargos en disputa.

La definición mínima adquiere mayor sentido cuando se traen a colación los demás rasgos identificados de la democracia: gradualidades en el proceso de democratización (acceso al voto), reglas constitutivas (definen qué califica como voluntad general) y precondiciones o reglas preliminares.

Bobbio reconoce tres precondiciones: la primera es la facultad de participar en la toma de decisiones, la segunda es la existencia de reglas procesales, y es necesaria la presencia de una tercera: "es indispensable que aquellos que están llamados a decidir o a elegir a quienes deberán decidir, se planteen alternativas reales y estén en condiciones de seleccionar entre una y otra". Para que esta condición se materialice, es necesario un instrumento que garantice los derechos fundamentales/inviolables del individuo. Desde su perspectiva "las normas constitucionales que atribuyen estos derechos no son propiamente reglas del juego: son reglas preliminares que permiten el desarrollo del juego". ${ }^{8}$

En el mismo sentido, Bovero distingue a las normas constitucionales como reglas preliminares del juego, reconociendo condiciones internas, y las precondiciones externas de la democracia. Califica de condiciones internas a los derechos políticos de libertad e igualdad y como precondiciones externas a aquellos derechos fundamentales "cuya violación puede comprometer y tornar en vano el ejercicio de los derechos políticos". ${ }^{9}$

Enseguida, el propio Bobbio enfatiza el papel central del individuo, de la persona en la democracia, cuando afirma "pero incluso las decisiones grupales son tomadas por individuos (el grupo como tal no decide)". ${ }^{10}$ Esta mención al individuo refiere a la concepción moderna del mismo, y lo separa de la concepción republicana del modelo clásico griego, donde la individualidad estaba supeditada a la comunidad. ${ }^{11}$

\footnotetext{
${ }^{7}$ Bobbio, Norberto, El futuro de la democracia, México, FCE, 2001, p. 26

${ }^{8}$ Bobbio, Norberto, El futuro de la democracia, México, FCE, 2001, p. 26. Por supuesto, Bobbio no es el único autor que se había percatado de estas precondiciones. Robert Dahl había detectado "las condiciones de procedimiento minimas" para la existencia de la democracia política moderna: "los ciudadanos tienen derecho a expresarse, sin el peligro de un castigo severo, sobre asuntos politicos definidos ampliamente [...] los ciudadanos tienen derecho a buscar fuentes alternativas de información. Además, las fuentes alternativas de información existen y están protegidas por la ley [...] Los ciudadanos también tienen derecho a formar asociaciones u organizaciones relativamente independientes, incluidos partidos políticos y grupos de interés que sean independientes". DAHL, ROBERT, Dilemmas of Pluralist Democracy, New Haven, Yale University Press, 1982, p. 11.

${ }^{9}$ Barboza Vergara, Antonio Carlos, "Democracia y derechos humanos en la teoria política de Norberto Bobbio", Co-herencia, vol. 2, núm. 3, 2005, p. 123.

${ }^{10}$ Bobbio, Norberto, El futuro de la democracia, México, FCE, 2001, p. 24.

${ }^{11}$ Aristóteles, Política, Madrid, Tecnos, 2005, p. 217.
} 
No obstante la centralidad del individuo, el autor reconoce que éste se encuentra constreñido, incentivado o influido por reglas externas, siguiendo la tradición institucionalista de la ciencia política. Explica que "para que una decisión tomada por individuos [...] pueda ser aceptada como una decisión colectiva, es necesario que sea tomada con base en reglas, (no importa si son escritas o consuetudinarias) que establecen quiénes son los individuos autorizados para tomar todas las decisiones obligatorias para todos los miembros del grupo y con qué procedimientos". ${ }^{12}$

Las condiciones preliminares ancladas en el papel central del individuo correspondiente a ciertos derechos humanos, civiles y políticos, junto con reglas electorales más equitativas, hicieron posible la transición de México hacia la democracia. Además, se ha reconocido que una democracia requiere de la presencia de ciertos derechos mínimos para tener sustancia; es decir, se enfatiza el carácter político y social de la democracia para su materialización.

"De esta forma, para ser real y no sólo aparente, la democracia tiene que ser liberal (política) y social al mismo tiempo."13 La democracia además de incluir las cuatro libertades de los modernos (personal, de asociación, de reunión y de pensamiento), requiere de precondiciones adecuadas para lograr su efectividad. No "puede considerarse plenamente democrático un sistema en el que algunos derechos sociales (aquellos mínimos necesarios para una vida digna) no se encuentran debidamente garantizados; según Bobbio estos derechos sociales fundamentales eran, al menos, tres: el derecho a la educación, al trabajo y a la salud". ${ }^{14}$

\section{Fortalecimiento de la democracia competitiva}

La democracia mínima es un conjunto de reglas que tienen por objeto sentar las bases de la competencia política porque "sin elecciones, sin la abierta competencia por el poder entre fuerzas sociales y agrupaciones políticas, no hay democracia". ${ }^{15} \mathrm{Si}$ aceptamos que la competencia no es suficiente porque "la

\footnotetext{
12 Bobilo, Norberto, El futuro de la democracia, México, FCE, 2001, p. 24

${ }^{13}$ Salazar, Pedro, "Democracia: ¿Formal o sustantiva? El problema de las precondiciones en la teoría de Norberto Bobbio", En Lorenzo Cordova y Pedro Salazar (coords.), Politica y derecho: (re)pensar a Bobbio, México, Siglo XXI, 2005, p. 245. Cursivas en el original.

${ }^{14}$ Salazar, Pedro, "Democracia: ¿Formal o sustantiva? El Problema de las precondiciones en la teoría de Norberto Bobbio", En Lorenzo Cordova y Pedro Salazar (coords.), Politica y derecho: (re)pensar a Bobbio, México, Siglo XXI, 2005, p. 246.

${ }^{15}$ Nohten, Dieter, Sistemas electorales y partidos políticos, México, Fondo de Cultura Económica, 1994, p. 12.
} 
competencia es una estructura o regla del juego; la competitividad es un estado concreto del juego". ${ }^{16}$ Entonces, para que el ciudadano realmente pueda elegir entre las distintas opciones, ${ }^{17}$ se requiere la existencia de partidos políticos, ofertas políticas reales, incertidumbre sobre los resultados de la competencia, traducción de sus ofertas en políticas gubernamentales y libertades básicas.

A partir del "indicador compuesto de competitividad", podemos dar cuenta de cómo la competencia en México se incrementó entre las distintas fuerzas políticas hasta alcanzar niveles competitivos. En ese sentido, se presenta evidencia empírica de cómo se fue fortaleciendo la democracia en el tiempo, un logro importante si se considera el pasado autoritario mexicano.

Tabla 1. Número de estados por nivel de competitividad, elecciones de presidente de la República, 1982-2006 ${ }^{18}$

\begin{tabular}{|c|c|c|c|c|c|}
\hline $\begin{array}{c}\text { Año/ } \\
\text { Nivel }\end{array}$ & \multicolumn{2}{c}{ No. } & \multicolumn{2}{c}{ Competitivo } & \multicolumn{2}{c|}{ Bajo } & \multicolumn{2}{c|}{ Medio } & alto \\
\hline 1982 & 32 & $21(65.6 \%)$ & $9(28.1 \%)$ & $2(6.2 \%)$ & \\
\hline 1988 & 32 & $3(9.4 \%)$ & $16(50 \%)$ & $13(40.6 \%)$ & \\
\hline 1994 & 32 & & $3(9.4 \%)$ & $29(90.6 \%)$ & \\
\hline 2000 & 32 & & & $22(68.7 \%)$ & $10(31.3 \%)$ \\
\hline 2006 & 32 & & & $16(50 \%)$ & $16(50 \%)$ \\
\hline
\end{tabular}

Fuente: Elaboración propia con base en MÉNDEZ DE HoYos, IRMA, Transición y consolidación democrática en México ¿es posible una regresión?, p. 72.

Si se consideran las elecciones presidenciales entre 1982 y 2006 en las entidades federativas, se registra un incremento general de la competitividad (tabla 1). En 1982, las elecciones no competitivas a lo largo del territorio mexicano correspondían a $65 \%$ de las entidades, mientras $28.1 \%$ correspondía al bajo y sólo $6.2 \%$ al medio. Para 1988, se observa un cambio cualitativo donde el no competitivo decreció a 9.4\%, el bajo incrementó a $50 \%$ y el alto pasó de 6 a $40 \%$.

\footnotetext{
${ }^{16}$ Sartori, Giovanni, Parties and Party System. A framework for analysis, Cambridge, Cambridge University Press, 1976, p. 218

${ }^{17}$ Véase en detalle la sección de estudios comparados del texto Méndez de Hoyos, IRMA, "Competencia y competitividad electoral: dos conceptos clave de la transición democrática", Polis. Investigación y Análisis Sociopolítico y Psicosocial, vol. 1, núm. 3, 2003, pp. 30-36.

${ }^{18}$ Datos basados en el indicador compuesto de competitividad (Ic). La fórmula para calcularlo es la siguiente: $\mathrm{IC}=$ $(100-M V)+F 0$ DV/ $\beta$, En donde: MV = Margen de Victoria, FO = Fuerza de la Oposición y DV = Desigualdad de distribución de victorias por partido. En términos operacionales, el ic mide el grado de competitividad de la elección a en el tiempo (t). Para hacerlo mide la distribución de la fuerza electoral de los partidos en una elección. El ıc se estima en porcentajes y tiene un rango de 0 a 100.
} 
En 1994 el nivel de competitividad media incrementó hasta $90 \%$, posteriormente, en la elección del 2000, ningún estado registró nivel de competitividad bajo. Aparece la categoría alto por primera vez en la historia del país con $31 \%$, mientras el nivel medio incrementa a $68 \%$. Para el año 2006, ambos niveles de competitividad, medio y alto, son de $50 \%$. La evidencia en su conjunto muestra un incremento claro de la competitividad electoral y, por lo tanto, un proceso de fortalecimiento democrático hacia principios del siglo XXI.

La tabla 2 presenta de igual manera un incremento de la competitividad en el periodo 1979-2006, considerando las elecciones federales de diputados de mayoría. Para 1982, 65.6\% de las entidades registraron elecciones de diputados no competitivas, $15 \%$ de nivel bajo, $18 \%$ nivel medio y ninguna en el nivel alto. Hacia 1994, sólo 9.4\% aparecía en el nivel bajo y el nivel medio alcanzó 90.6\% de las entidades del país. En 2006, 43.8 \% correspondió al nivel medio y $56.2 \%$ registraron nivel competitivo alto.

Tabla 2. Estados por nivel de competitividad, elecciones federales de diputados de mayoría, 1979-2006

\begin{tabular}{|c|c|c|c|c|c|}
\hline $\begin{array}{l}\text { Año/ } \\
\text { Nivel }^{*}\end{array}$ & $\mathrm{~N}$ & No & Bajo & Medio & Alto \\
\hline 1982 & 32 & $21(65.6 \%)$ & $5(15.6 \%)$ & $6(18.7 \%)$ & \\
\hline 1985 & 32 & $16(50 \%)$ & $12(37.5)$ & $4(12.5 \%)$ & \\
\hline 1988 & 32 & $3(9.4 \%)$ & $17(53.1 \%)$ & $11(34.4 \%)$ & $1(3.1 \%)$ \\
\hline 1991 & 32 & $8(25 \%)$ & $16(50 \%)$ & $8(25 \%)$ & \\
\hline 1994 & 32 & & $3(9.4 \%)$ & $29(90.6 \%)$ & \\
\hline 1997 & 32 & & & $28(87.5 \%)$ & $4(12.5 \%)$ \\
\hline 2000 & 32 & & & $20(62.5 \%)$ & $12(37.5 \%)$ \\
\hline 2003 & 32 & & & $27(84.4 \%)$ & $5(15.6 \%)$ \\
\hline 2006 & 32 & & & $14(43.8 \%)$ & $18(56.2 \%)$ \\
\hline
\end{tabular}

Fuente: Elaboración propia con base en MÉNDEZ DE HoYos, IRMA, Transición y consolidación democrática en México ¿es posible una regresión?, p. 74

* El rango de valores para los niveles de competitividad son: no competitivo, de 0 a 14.999\%; bajo, de 15 a 23.999\%; medio, de 24 a 44.999\%; alto, de 45 a 100\%. Las elecciones federales incluyen a la Ciudad de México, por lo que en total suman 32 entidades. 
Mientras México profundizaba en la consolidación de su democracia a partir de lo electoral, se generaron expectativas de que con la alternancia partidista y la oposición en el Congreso, la protección de los derechos humanos se incrementaría. Esta creciente expectativa tenía una vertiente internacional-regional de los derechos humanos y una vertiente proveniente de la literatura especializada.

En relación con la primera (la dimensión internacional/regional de los derechos humanos), se puede aceptar que, a partir de la Declaración Universal de los Derechos del Hombre, ${ }^{19}$ el sistema internacional de los derechos humanos experimentó un desarrollo continuo y creciente. Regionalmente, el avance del sistema interamericano en la materia se intensificó a partir de la década de los ochenta, durante el periodo de transición de las dictaduras latinoamericanas hacia la democracia. ${ }^{20}$

En el caso de México se observa una transición tardía al sistema democrático en relación con los demás países de la región, igual que una tardía integración al sistema interamericano de los derechos humanos. Fue hasta el 10 de junio de 2011 que se adoptó en México una paradigmática reforma constitucional en materia de derechos humanos. ${ }^{21}$

Esta reforma resultó de una serie de eventos: primero, el reconocimiento de México a la competencia contenciosa de la Corte Interamericana de Derechos Humanos el 16 de diciembre de 1998; posteriormente, dos sentencias emitidas por ésta: en 2008, la sentencia del caso Castañeda Gutman vs. Estados Unidos Mexicanos y, en 2009, la sentencia del caso Radillo Pacheco vs. Estados Unidos Mexicanos, ambas condenatorias; finalmente, la sentencia emitida por la Corte Constitucional Mexicana en el expediente varios 912/2010. Todos estos eventos derivaron en una profunda reforma que otorgó el rango constitucional a los tratados internacionales de derechos humanos e incluye el mandato de control de constitucionalidad y del principio pro persona. ${ }^{22}$

\footnotetext{
${ }^{19}$ Posteriormente en 1993, con la Declaración de Viena, se establece la interdependencia e universalidad de todos los derechos humanos, sin distinciones. Se establecen como principios la universalidad, interdependencia, indivisibilidad y progresividad de los derechos humanos: todos los derechos para todas y todos. Además, clarifican la jerarquía de los tratados en esta materia. Hoy podemos decir que la democracia en sus principios propone elementos como el de universalidad, igualdad, equidad e indivisibilidad.

${ }^{20}$ Bogdandy, Armin Von, Morales Antoniazzi, Mariela y Ferrer Macgregor, Eduardo, lus Contitutionale Commune en Derecho Humanos en América Latina, México, Porrúa, ImdPc, mapil, 2013, p. 8; Serrano, Sandra y Vázouez, Daniel, Los derechos en acción: obligaciones y principios de derechos humanos, México, Flacso, 2013, pp. 47-49; BogdANDY, ARMIN Von, lus constitutionale commune en América Latina. Rasgos, potencialidades y desafíos, México, unAm - Instituto Max Planck de Derecho Público comparado y Derecho Internacional, 2014, pp. 3-23; TRINDAdE, Antonio, International law for human kind: towards a New lus Gentium, Netherlands, Martinus Nijhoff Publishers, 2010, p. 25.

${ }^{21}$ Mientras en la mayoria de los paises de la región la inserción se registró al termino de las dictaduras en la década de los ochenta.

${ }^{22}$ Corzo Sosa, Edgar, Carmona Tinoco, Jorge Ulises, Saavedra Alessandrini, Pablo, El impacto de las Sentencias de la Corte
} 
En este contexto nos parece pertinente retomar la afirmación de Bobbio respecto al Estado liberal como base histórica y jurídica del Estado democrático. Más aún, tanto el Estado liberal como el Estado democrático son interdependientes en cuanto a que ciertas libertades son necesarias para el correcto ejercicio del poder democrático y éste es indispensable para garantizar la existencia y persistencia de las libertades fundamentales. ${ }^{23}$

Siguiendo la postura de la teoría democrática procedimental, podemos inferir que la democracia evoluciona en el sentido de que se dirige hacia el fortalecimiento de sus precondiciones; esto es, los derechos humanos, los cuales experimentan actualmente un notorio proceso de fortalecimiento y consolidación.

La segunda vertiente proviene de la literatura especializada. Ésta demostraba cómo las sociedades democráticas de larga tradición presentaban menores violaciones a los derechos humanos. La relación estrecha entre democracia y los derechos humanos ${ }^{24}$ tiene sentido porque se requieren libertades necesarias para el apropiado ejercicio del poder democrático, relación documentada en la literatura comparada sobre democratización y derechos humanos. ${ }^{25}$ Para

Interamericana de Derechos Humanos, México, Tirant lo Blanch, 2013, pp. 20-22. CARmona Tinoco, Jorge Ulises, "La reforma y las normas de derechos humanos" en Miguel Carbonell, Pedro Salazar, La Reforma Constitucional de Derechos Humanos: Un Nuevo Paradigma, pp. 39-42, México, unam, 2014, pp. 39-42.

${ }^{23}$ BobBio, Norberto, El futuro de la democracia, México, FCE, 2001, pp. 26-27.

${ }^{24}$ La mayor o menor protección de los derechos humanos no se explica solamente por la variable democracia, es decir, no se asume que la democracia incide de manera causal sobre la protección de los derechos humanos. En todo caso, queremos abonar a la discusión teórica de los estudios que vinculan democracia y protección de los derechos humanos. Desde nuestra perspectiva, esa teoría no ha sido puesta a prueba en contextos como el mexicano, y por lo tanto "en qué medida nos ayuda dicha teoría a explicar el mundo". King, Gary, KeOhane, Robert y Verba, Sidney, El diseño de la investigación social, Madrid, Alianza editorial, 2000, p. 112 y Cfr. POPPER, KARL, La lógica de la investigación científica, Madrid, Tecnos, 1985. Los autores citados en el texto -Bobbio, Bovero y Dahl-, son quienes explícitamente reconocen que las reglas mínimas de la democracia tienen eficacia si además de concebir a los individuos-personas, éstos tienen condiciones favorables para incidir en la política. Si partimos de concebir la propuesta teórica de dichos autores como "un sistema hipotético-deductivo, es decir un sistema de hipótesis dentro del que se pueden construir argumentos válidos (esto es, cadenas deductivas)", estamos en posibilidad de visualizar el alcance empírico de sus proposiciones-afirmaciones. Bunge, MARIO, Buscar la filosofia en las ciencias sociales, México, Siglo XXI, 2007, p. 166. Una recomendación metodológica en este sentido es "generar tantas consecuencias observables como sea posible". King, Gary, Keohane, Robert O. y Verba, Sidney, El diseño de la investigación social, Madrid, Alianza editorial, 2000, p. 30. Más adelante subrayan: "cada consecuencia adicional de nuestra teoría que observemos [sic] aportará un nuevo contexto en el que poner a prueba su veracidad. Cuantas más consecuencias observables encontremos que sean coherentes con la teoria, más penetrante será la explicación y más ciertos sus resultados". King, Gary, KeOHane, RoBert O. y Verba, Sidney, El diseño de la investigación social, Madrid, Alianza editorial, 2000, p. 34. En este sentido, al establecerse empíricamente una democracia en México una consecuencia empírica que debería de observarse es la tendencia decreciente de quejas sobre violaciones a los derechos humanos.

${ }^{25}$ Vázouez, Daniel, "Los derechos humanos y la teoría y estudios empíricos sobre la democracia", en Ariadna Estévez y Daniel Vázquez (eds.), Los derechos humanos en las ciencias sociales: una perspectiva multidisciplinaria, México, Flacso - UnAm, 2010, pp. 221-259. 
el caso de las democracias consolidadas se espera la disminución de las violaciones a los derechos humanos. ${ }^{26}$

Esta postura se basa en diversos estudios comparativos a escala global con hallazgos coincidentes en cuanto a la presencia de una relación negativa entre ambas variables. En contraste, para las democracias no consolidadas, la literatura especializada prevé un incremento a las violaciones de los derechos humanos. En regímenes establecidos, tanto autoritarios como democráticos, la violación a los derechos humanos decrece porque ofrecen posturas claras para los ciudadanos en caso de que haya violaciones a los derechos humanos. Sin embargo, cuando estos son débiles, es decir, cuando una dictadura es débil y una democracia es nueva, las violaciones aumentan debido a las llamadas "incoherencias sistemáticas". Este concepto engloba la ausencia de reglas, formales e informales, claras. ${ }^{27}$

La presencia de un régimen democrático debería verse reflejada en el incremento de la promoción y respeto a los derechos humanos. En consecuencia, la evidencia debería demostrar un decremento de las violaciones a los derechos humanos. La hipótesis principal es que, a mayor consolidación de la democracia con el tiempo, debería observarse una disminución de las quejas interpuestas sobre violaciones a los derechos humanos. La hipótesis alternativa es que, en nuevas democracias como el caso mexicano, debería de registrarse un incremento de las violaciones a los derechos humanos.

\section{Evidencia empírica}

Para el registro empírico se eligió el indicador proporcionado por la Comisión Nacional de los Derechos Humanos ( $\mathrm{CNDH}$ ) por constituir el órgano por excelencia para la protección de los derechos humanos en el Estado mexicano. La CNDH

${ }^{26}$ Los gobiernos democráticos cuenta con condiciones menos favorables para la violación sistemática de derechos humanos ya que los ciudadanos tienen acceso a más y mejores mecanismos para garantizarlos. La literatura identifica estas condiciones como: 1) la existencia de ciertos derechos civiles y políticos cómo precondiciones de la democracia; 2) la rendición de cuentas (accountability vertical) presente en el voto de los electores; 3 ) la capacidad del ciudadano de acudir a diferentes instancias para denunciar y exigir las protección de sus derechos (accountabiliy horizontal), lo que reduce la tensión social y por lo tanto la probabilidad de acciones represivas por parte del estado; 4) un gobierno democrático es más receptivo a las demandas ciudadanas. VÁzouez, DanieL, "Los derechos humanos y la teoria y estudios empíricos sobre la democracia", en Ariadna Estévez y Daniel Vázquez (eds.), Los derechos humanos en las ciencias sociales: una perspectiva multidisciplinaria, México, Flacso - UnAm, 2010, p. 249.

${ }^{27}$ FEIN, HeLEN, "More Murder in the Middle: Life-Integrity Violations and Democracy in the World", Human Rights Quarterly, vol.17, pp. 170-191; KING, JOHN, "Repression, Domestic Threat and Interactions in Argentina and Chile", Journal of Political and Military Sociology, núm. 6, 1998, pp. 191-211; Regan, Patrick, Hendersons, Errol, "Democracy Threats and Political Repression in Developing Countries: Are Democracies Internally Less Violent?", Third World Quarterly, núm. 1, 2002, pp. 119-136. 
es un órgano constitucional de carácter autónomo y representa la fuente oficial de información, particularmente en relación con las quejas que se gestionaron ante la misma, y las que se podrían atender y resolver de manera oficial. ${ }^{28}$

El comportamiento de los datos, según se visualiza en la gráfica, es revelador, a pesar de su incipiente documentación. ${ }^{29}$ Considerando la hipótesis principal, la evidencia se confirma parcialmente porque se observa una disminución en el periodo 2000-2004. En los primeros cuatro años del primer gobierno de alternancia con Vicente Fox las cifras tienden a la baja, como lo sugiere la literatura que considera democracias consolidadas.

Los siguientes tres años, con Felipe Calderón en la presidencia (2006-2012), literalmente la tendencia oscila entre 6000 y 8000 quejas sobre presuntas violaciones a los derechos humanos. De 2005 a 2009 la tendencia oscila entre 6000 y 8000 quejas sobre presuntas violaciones a los derechos humanos. En 2010 empieza una clara tendencia a la alza, fecha a partir de la cual las cifras tienen un incremento de entre 1000 y 2000 quejas por año. Así, de comenzar el sexenio de Calderón con 6000 quejas, terminó con el doble: 12 000. Este repunte es inexplicable para la hipótesis principal.

$\mathrm{Si}$, en cambio, ponemos en consideración la hipótesis rival, entonces esperaríamos que para el caso mexicano se registrara un incremento sistemático de las violaciones de los derechos humanos. Sin embargo, de nuevo se confirma parcialmente. La segunda hipótesis no aplica para la tendencia en el periodo 2000-2004; sólo aplicaría para el segundo periodo analizado, es decir, las cifras concuerdan con la expectativa teórica del incremento de violaciones en nuevas democracias.

Hasta aquí, podemos afirmar que ninguna de las dos hipótesis se sostiene en el caso mexicano. Ambas aplicarían para explicar sólo parcialmente las violaciones de derechos humanos de nuestro país. En todo caso, creemos que de forma incipiente se está mostrando un nuevo patrón distinto a los revisados por la literatura especializada, cuyo rasgo central sería la inestabilidad de las tendencias. El caso mexicano no se comporta como la teoría espera de una nueva democracia.

\footnotetext{
${ }^{28}$ Si bien existen otras fuentes de información, estas no reportan el número de quejas interpuesto ante la CNDH. Es importante mencionar que los datos disponibles de organismos internacionales y ong (Organización de Estados Americanos, Human Rights Watch, la Comisión Interamericana de los Derechos Humanos) confirman la tendencia de la CNDH hacia nuestro interés y no a la cantidad nominal. Por supuesto, no todas las quejas se traducen en violaciones efectivas reconocidas por el organismo que las recibe; pero para nosotros, las quejas sobre violaciones a los derechos humanos expresan el malestar ciudadano respecto de la violación de sus derechos y éste toma la iniciativa de concretar su malestar ante un organismo para que éste garantice sus derechos, en tanto es un órgano responsable establecido con ese propósito organizacional e institucional.

${ }^{29}$ Los datos son nominales; sin embargo, no conocemos la cantidad exacta de quejas que el organismo autónomo calificó efectivamente como violaciones a los derechos humanos.
} 
Quejas interpuestas como presuntas violaciones a los derechos humanos

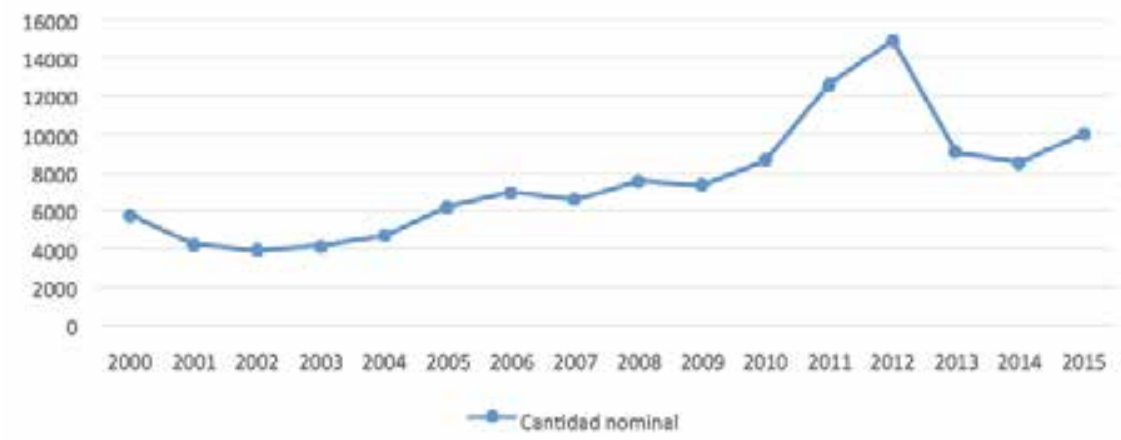

Fuente: elaboración propia con base en la información de la Comisión Nacional de los Derechos Humanos, Informes anuales 2000-2015

En ese sentido, cuando se observan los registros de 2010 y 2011 -los años de mayor repunte nominal-, hay un doble problema. Por un lado, los mayores niveles de violaciones a los derechos humanos coinciden con los mayores niveles de violencia derivados de la política de combate al crimen organizado del presidente Calderón. Por otro lado, coincide con el año en que institucionalmente el Estado mexicano reconoció en todas sus esferas el principio pro persona. Pues, con ello, instrumentó a nivel organizacional y operativo una política transversal de derechos humanos a favor de la persona, antes que circunscrita al ciudadano. En ese sentido, las mayores quejas pueden atribuirse a la misma apertura institucional, y no sólo al mayor crecimiento de las violaciones.

De esta manera, el caso mexicano muestra los límites de las proposiciones teóricas ampliamente aceptadas para explicar los derechos humanos en otros países. Desde nuestro punto de vista, el primer periodo, efectivamente, estaba mostrando los avances que en la materia de derechos humanos se gestaban en la región latinoamericana desde los años noventa. Pero dicha tendencia cambió cuando se puso en marcha la política de combate al crimen organizado en el sexenio de Calderón.

La corrupción de las policías, la impericia de los militares en tareas de seguridad civil, la descoordinación de las autoridades federales y subnacionales, el combate armado constante, el lavado de dinero, la corrupción gubernamental y hasta la debilidad institucional, pusieron en riesgo los derechos humanos (integridad física) y libertades (expresión, tránsito, asociación, votar y ser votado) de nuestra democracia. Al vulnerarse los derechos humanos y libertades 
a lo largo y ancho del territorio nacional, debido a los altos niveles de violencia, la democracia conseguida comenzó un proceso de regresión o debilitamiento.

Vale la pena indicar dos observaciones. La primera se relaciona con el régimen democrático. Por un lado, la teoría democrática sostiene como un aspecto fundamental la persistencia de un régimen democrático y, sobre todo, del apoyo ciudadano que la revitalice frente a otras formas de gobierno. ${ }^{30}$ Aquí falta introducir datos específicos que indicaran cuál es el apoyo del ciudadano respecto a su democracia, pues es posible sugerir que la creciente madurez de la democracia podría incentivar la mayor participación y queja de la ciudadanía frente a sus autoridades. De ser así, los datos presentados serían una incipiente noticia positiva para nuestro país.

La segunda observación se vincula con políticas públicas o problemas sociales específicos que podrían estar sesgando los datos presentados. Al inicio de su administración, Felipe Calderón incorporó dentro de su agenda el combate al crimen organizado y narcotráfico como la mayor prioridad. En consecuencia, el efecto no deseado de esta política gubernamental fue el incremento de la violencia y las quejas sobre afectación a los derechos humanos, en tanto se usó desmedidamente al ejército y a la policía en su combate.

La tarea pendiente es utilizar otras variables para controlar el efecto del combate al crimen organizado. Así, se verá si este fenómeno contaminó la disminución de las quejas a las violaciones de los derechos, en tanto la consolidación del régimen democrático; o si el crecimiento es propio de la democracia y el crecimiento es a su vez incentivado por la política criminal.

Más allá de que los datos utilizados a partir de la Comisión Nacional de Derechos Humanos sean discutibles, otras fuentes, como los datos de la Comisión Interamericana de Derechos Humanos (CIDH) también confirman un repunte considerable a partir de 2011 en México. En este año se recibieron 273 peticiones; para 2012, fueron 431; en 2013, alcanzaron 660; en 2014, descendieron a 500; y alcanzaron la cifra histórica de 849, en 2015. En cuatro años se recibieron tres veces más. ${ }^{31}$

Si todavía hay duda del irregular crecimiento de las cifras, la perspectiva comparativa funciona mejor en el contexto regional, donde nuestro país recibió la mayor cantidad de peticiones ante el sistema interamericano. Según los

\footnotetext{
${ }_{30}$ SHIN, Doн ChulL, "Democratization: perspectives from Global Citizenries", en Russell Dalton y Hans-Dieter Klingemann (eds.), Oxford Handbook of Political Behaviour, Oxford, Oxford University Press, 2007, pp. 268-275.

${ }^{31}$ Comisión Interamericana de Derechos Humanos, "Estadisticas". [Consulta: el 19 de septiembre, 2016]. Disponible en: http://www.oas.org/es/cidh/multimedia/estadisticas/estadisticas.html
} 
registros de la CIDH, en 2015, México tuvo un registro de 849, seguido muy de lejos por Colombia, con 419 -la mitad del caso mexicano- y Argentina, con 164 -casi ocho veces menos-.

\section{Conclusiones}

La teoría de la democracia sigue ofreciendo herramientas de gran valor para el análisis de la política contemporánea. Como se revisó en la primera parte, en ella se encuentran diversas formas de concebir a la democracia. En particular el enfoque procedimental es el que mejor explica la construcción de la democracia mexicana centrada en reformas electorales.

Las aportaciones de Bobbio, en este sentido, siguen siendo de vital importancia, en tanto vincula a la democracia con el reconocimiento de ciertas precondiciones para que la misma florezca. Sin ellas, de nada servirían las reglas de quién elige y bajo qué reglas. La consagración de la democracia adquiere su mayor fuerza cuando se vincula a la lógica de los derechos humanos.

Si bien la expectativa teórica es que en democracias consolidadas disminuyan las violaciones a los derechos humanos, en tanto el Gobierno o los órganos del Estado observan su vigencia y protección, la evidencia no es contundente para el caso mexicano. Pero tampoco es contundente la evidencia que se encontró para la hipótesis alterna, según la cual en países de reciente democracia se esperaría un incremento sistemático de las violaciones a los derechos humanos.

Tenemos evidencia incipiente de que el caso mexicano es un caso anormal, en tanto no se ajusta a la teoría que espera el fortalecimiento de la democracia asociada a menores violaciones de los derechos humanos. Tampoco se ajusta a la proposición según la cual en una democracia no consolidada debería registrarse sistemáticamente el incremento de violaciones de derechos humanos.

En este sentido, vale la pena señalar los caminos de la agenda futura de investigación. Un primer punto sería realizar estudios comparativos en la región latinoamericana, en países de reciente democracia. Asimismo se tendría que desagregar la comparación a nivel de las entidades federativas en México, para incrementar el número de observaciones y validar mejor la tendencia registrada en la esfera federal.

El segundo es indagar si el mismo régimen incentiva o promociona que las personas denuncien la violación de los derechos humanos. De esa forma, se podría verificar si el incremento de las quejas es un registro de la ampliación de su derecho a denunciar y controlar los actos del poder público. Además, sería 
pertinente explorar si el incremento del acceso a la tecnología de la información incrementa la denuncia.

Un tercer punto de la agenda es evaluar hasta qué punto la instrumentación de la reforma y su traducción institucional-organizacional fue la adecuada y camina en la dirección correcta. Algunos estudios sugieren que la reforma constitucional no es suficiente. Por ello, se requiere analizar en detalle el diseño institucional de los órganos encargados de la vigilancia y protección de los derechos humanos, ${ }^{32}$ o las propias reglas electorales que desincentivan el compromiso de los representantes políticos respecto a los derechos humanos. ${ }^{33}$

En el caso específico de México, podemos afirmar que la reforma constitucional del 2011, la cual establece la primacía jerárquica de los instrumentos internacionales en materia de derechos humanos, implica un paso firme e irreversible hacia el fortalecimiento de las precondiciones democráticas. Por lo tanto, esta reforma fortalece el régimen democrático imperante, el cual tendrá efectos en la calidad de vida civil y política de sus ciudadanos. ${ }^{34}$

Sin embargo, mientras empíricamente no se registren niveles menores sobre violaciones a los derechos humanos, ${ }^{35}$ debido a las políticas de combate al crimen organizado, las reformas constitucionales, institucionales y organizativas no serán suficientes para mejorar la relación del Estado con las personas. En ese sentido, persistirá el círculo vicioso en la comunidad política de la cual formamos parte.

\footnotetext{
${ }^{32}$ FINKEL, JoDI, "Explaining the Failure of Mexico's National Commission of Human Rights (Ombudsman's Office) after Democratization: Elections, Incentives, and Unaccountability in the Mexican Senate", Hum Rights Rev, vol. 13, 2012, pp. 473-495.

${ }^{33}$ Cingranell, David y Mikhail, Filippov, "Electoral Rules and Incentives to Protect Human Rights", The Journal of Politics, vol. 72, núm. 1, 2010, pp. 243-257. Moreno, ERIKA, "The Contributions of the Ombudsman to Human Rights in Latin America, 2016, 1982-2011", Latin American Politics and Society, vol. 58, núm. 1, pp. 98-120.

34 "El reconocimiento y protección de los derechos humanos están en la base de la Constituciones democráticas modernas. La paz es a su vez el presupuesto necesario para el reconocimiento y la efectiva protección de los derechos humanos, tanto en los Estados como en el sistema internacional. Al mismo tiempo, el proceso de democratización del sistema internacional, que es el camino obligado para la realización del ideal de la 'paz perpetua', en el sentido kantiano de la palabra, no puede avanzar sin una extensión gradual del reconocimiento y protección de los derechos humanos por encima de los Estados. Humanos, democracia y paz son tres elementos necesarios del mismo movimiento histórico: sin derechos humanos reconocidos y protegidos no hay democracia, sin democracia no existen las condiciones mínimas para la solución pacifica de conflictos." Bobbio, Norberto, El tiempo de los derechos, Madrid, Sistema, 1991, p. 14.

${ }^{35}$ VÁzouez, Daniel, "Los derechos humanos y la teoría y estudios empíricos sobre la democracia", en Ariadna Estévez y Daniel Vázquez (eds.), Los derechos humanos en las ciencias sociales: una perspectiva multidisciplinaria, México, Flacso - UnAm, 2010, pp. 221-259.
} 


\section{Bibliografía}

Aristóteles, Politica, Madrid, Tecnos, 2005.

Barboza Vergara, Antonio Carlos, "Democracia y derechos humanos en la teoría política de Norberto Bobbio", Co-herencia, vol. 2, núm. 3, 2005.

BobBio, Norberto, El futuro de la democracia, México, FCE, 2001.

BobBio, Norberto, El tiempo de los derechos, Madrid, Sistema, 1991.

Bogdandy, Armin Von, Ius constitutionale commune en América Latina. Rasgos, potencialidades y desafíos, México, unam - Instituto Max Planck de Derecho Público comparado y Derecho Internacional, 2014.

Bogdandy, Armin Von, Morales Antoniazzi, Mariela y Ferrer Macgregor, Eduardo, Ius

Contitutionale Commune en Derecho Humanos en América Latina, México, Porrúa, IMDPC, MAPIL, 2013.

Bunge, Mario, Buscar la filosofía en las ciencias sociales, México, Siglo XXI, 2007. Carmona Tinoco, Jorge Ulises, "La reforma y las normas de derechos humanos" en Miguel Carbonell, Pedro Salazar, La Reforma Constitucional de Derechos Humanos: Un Nuevo Paradigma, pp. 39-42, México, unam, 2014.

Christiano, Thomas, "An Instrumental Argument for a Human Right to Democracy", Philosophy \&t Public Affairs, vol. 39, núm. 2, 2011.

Cingranelli, David y Mikhail, Filippov, "Electoral Rules and Incentives to Protect Human Rights", The Journal of Politics, vol. 72, núm. 1, 2010.

Comisión Interamericana de Derechos Humanos, "Estadísticas". [Consulta: el 19 de septiembre, 2016]. Disponible en: http://www.oas.org/es/cidh/multimedia/estadisticas/estadisticas.html

Corzo Sosa, Edgar, Carmona Tinoco, Jorge Ulises, Saavedra Alessandrini, Pablo, El impacto de las Sentencias de la Corte Interamericana de Derechos Humanos, México, Tirant lo Blanch, 2013.

DAHL, RoBert, Dilemmas of Pluralist Democracy, New Haven, Yale University Press, 1982.

DAHL, ROBERT, La democracia y sus críticos, Barcelona, Paidós, 1992.

Davenport, Christian, "Multi-Dimentional Threat Perception and State Repression: An Inquiry into Why States Apply Negative Sanctions", American Journal of Political Science. American Journal of Political Science, núm. 39, 1995.

Diamond, Larry, Democracy in Developing Countries: Latin America, Londres, Lynne Rierner, 1999.

Durand Ponte, Víctor Manuel, Ciudadania y cultura politica en México, 1993-2001, México, Siglo XXI, 2004.

Fein, Helen, "More Murder in the Middle: Life-Integrity Violations and Democracy in the World", Human Rights Quarterly, vol.17.

FinKel, JoDI, "Explaining the Failure of Mexico's National Commission of Human Rights (Ombudsman's Office) after Democratization: Elections, Incentives, and Unaccountability in the Mexican Senate", Hum Rights Rev, vol. 13, 2012. 
GrepPI, Andrea, “Definiciones y reglas de la Democracia”, en Lorenzo Cordova y Pedro Salazar (coords.), Politica y derecho: (re) pensar a Bobbio, México, Siglo XXI, 2005.

Henderson, Conway, “Conditions Affecting the Use of Political Repression”, Journal of Conflict Resolution, vol. 35, 1999.

Hillebrecht, Courtnry, Mitchell, Dona-Gene y Wals C., Sergio, "Perceived human rights and support for new democracies: lessons from Mexico”, Democratization, vol. 22, núm. 7, 2015.

Howard, Rhoda E. y Jack Donnelly, "Human Dignity, Human Rights, and Political Regimes”, American Political Science Review, vol. 80, núm. 3, 2010, pp. 801-817.

King, Gary, Keohane, Robert O. Et Verba, Sidney, El diseño de la investigación social, Madrid, Alianza editorial, 2000.

KInG, John, "Repression, Domestic Threat and Interactions in Argentina and Chile”, Journal of Political and Military Sociology, núm. 6, 1998.

Landman, Todd, Politica comparada. Una introducción a su objeto y métodos de investigación, Madrid, Alianza, 2011.

MÉNDEZ DE Hoyos, IRMA, "Competencia y competitividad electoral: dos conceptos clave de la transición democrática," Polis. Investigación y Análisis Sociopolitico y Psicosocial, vol. 1, núm. 3, 2003, pp. 27-48.

MÉndeZ DE Hoyos, IRMA, “Transición y consolidación democrática en México ¿es posible una regresión?”, Revista de la Facultad de Derechos de México, núm. 247, 2007.

Moreno, ERIKA, "The Contributions of the Ombudsman to Human Rights in Latin America, 2016, 1982-2011", Latin American Politics and Society, vol. 58, núm. 1.

Nohlen, Dieter, Sistemas electorales y partidos politicos, México, Fondo de Cultura Económica, 1994.

Poe, Steven, Tate, Neal \& Camp, Linda, "Repression of the Human Right to Personal Integrity Revisited: A Global Cross National Study Covering 1976-1993”, International Studies Quarterly, vol. 43, 1999.

Poe, Steven, Tate, Neal, "Repression and Human Rights to Personal Integrity in the 1980s: A Global Analysis”, American Political Science Review, vol. 43.

Popper, Karl, La lógica de la investigación científica, Madrid, Tecnos, 1985.

Regan, Patrick, Hendersons, Errol, "Democracy Threats and Political Repression in Developing Countries: Are Democracies Internally Less Violent?”, Third World Quarterly, núm. 1, 2002.

SAlAZAR, Pedro, "Democracia: ¿Formal o sustantiva? El Problema de las precondiciones en la teoría de Norberto Bobbio”, En Lorenzo Cordova y Pedro Salazar (coords.), Politica y derecho: (re)pensar a Bobbio, México, Siglo XXI, 2005.

Sartori, Giovanni, Parties and Party System. A framework for analysis, Cambridge, Cambridge University Press, 1976. 
Schmitter, Phillipe C. y Terry L. Karl, "What Democracy is... and is not", en Larry Diamond y Marc F. Plattner (eds.), The Global Resurgence of Democracy, Baltimore, Johns Hopkins University Press, 1996.

SerRano, SANDRa y VÁzquez, Daniel, Los derechos en acción: obligaciones y principios de derechos humanos, México, Flacso, 2013.

Shin, Doн Chul, "Democratization: perspectives from Global Citizenries", en Russell Dalton y Hans-Dieter Klingemann (eds.), Oxford Handbook of Political Behaviour, Oxford, Oxford University Press, 2007.

Smith, Peter H., y Melissa R. Ziegler, "Liberal and Illiberal Democracy in Latin America”, Latin American Politics and Society, vol. 50, núm. 1, 2008, pp. 31-57.

Tilly, Charles, Democracy, Cambridge, Cambridge University Press, 2007.

TRINDADE, ANTonio, International law for human kind: towards a New Ius Gentium, Netherlands, Martinus Nijhoff Publishers, 2010.

VÁzquez, Daniel, "Los derechos humanos y la teoría y estudios empíricos sobre la democracia”, en Ariadna Estévez y Daniel Vázquez (eds.), Los derechos humanos en las ciencias sociales: una perspectiva multidisciplinaria, México, Flacso - UNAM, 2010. 